revista do ieb n 45 p. 107-122 set 2007

\title{
Mon chèr élève: Charles Koechlin, professor de Camargo Guarnieri
}

Flávia Camargo Toni ${ }^{2}$

Resumo

Compositor de ofício, Camargo Guarnieri ganhou uma bolsa de estudos para se aperfeiçoar e elegeu Charles Koechlin, autor de sólida bibliografia, como professor. Nas memórias colecionadas pelo músico brasileiro, no entanto, o caderno das aulas indica que o aluno trabalhou noções elementares de harmonia e contraponto, o que não condiz com o gabarito de nenhum deles. A análise da documentação pertencente aos acervos dos dois artistas tenta elucidar quais motivos levaram Guarnieri a escolher aquele que foi, coincidentemente, mestre de Fernando LopesGraça, autor português.

\section{Palavras-chave}

Camargo Guarnieri, Fernando Lopes-Graça, Charles Koechlin, Mário de Andrade, música brasileira, musicologia.

1 Texto resultante de apresentações orais que focalizaram a relação de amizade e trabalho entre Camargo Guarnieri e Fernando Lopes-Graça, e entre Camargo Guarnieri e Charles Koechlin, em colóquios ocorridos em abril ( 0 artista como intelectual: no centenário de Fernando Lopes Graça, Universidade de Coimbra, Portugal) e novembro de 2006 (Colloque International Charles Koechlin, Sorbonne, França), respectivamente.

2 Livre-Docente do Instituto de Estudos Brasileiros e do Programa de Pós-Graduação em Musicologia da Escola de Comunicações e Artes, da Universidade de São Paulo. Possui Bolsa de Produtividade em Pesquisa do CNPq - Nivel 2. 
revista do ieb n 45 p. 107-122 set 2007

\title{
Mon chèr élève: Charles Koechlin, Camargo Guarnieri's teacher
}

Flávia Camargo Toni

\begin{abstract}
As a professional composer, Camargo Guarnieri received a grant to continue his studies and chose Charles Koechlin as his teacher. Exploring primary sources belonging to personal archives, the article tries to elucidate the reasons that led Guarnieri to choose Koechlin - who was, by coincidence, Fernando Lopes-Graça's teacher.
\end{abstract}

\section{Keywords}

Camargo Guarnieri, Fernando Lopes-Graça, Charles Koechlin, Mário de Andrade, Brazilian music, musicology. 
Por mais de uma vez Camargo Guarnieri declarou ter outros dois pais, além de Miguel, o pai biológico, elegendo para tal categoria dois de seus professores e amigos, Lamberto Baldi e Mário de Andrade. Até 1945 - ano da morte de Mário - Guarnieri esteve fisicamente mais próximo do mestre brasileiro, já que em 1931 Baldi se mudara para o Uruguai. De qualquer forma, os temas de trabalho abordados com cada um deles diferiam bastante, como explicou o compositor:

Do ponto de vista da técnica de composição, devo a Lamberto Baldi os ensinamentos mais eficazes e que constituem os princípios básicos que ainda hoje adoto. Quanto à orientação estética, foi no convívio de Mário de Andrade que aprendi a contrariar, por assim dizer, os cânones consagrados das três escolas tradicionais de música. Mário de Andrade foi o grande teorizador da música brasileira e sua influência, posso assegurar, não se fez sentir somente sobre mim, que fui seu discípulo durante toda a vida, mas sobre toda uma geração de músicos brasileiros seus contemporâneos. Mesmo os novos compositores do Brasil refletem, direta ou indiretamente, a influência desse espírito admirável, cujos ensinamentos permanecem vivos e atuais. ${ }^{3}$

0 tipo de orientação que Camargo Guarnieri recebia do crítico e musicólogo paulista foi bem ilustrado quando, em 1934, os dois discutiram a gênese da Sonata $n^{\circ} 2$ para violino e piano: tentando adotar uma técnica diversa de trabalho com seu pupilo, por acreditar que no papel "as coisas ficam mais perfeitamente reconhecíveis", Mário escreveu uma primeira carta em tom bastante provocativo, obrigando o aluno a responder.

Com Lamberto Baldi, o aconselhamento profissional estendeu-se por toda a vida, também alimentado pela troca de cartas, mais intensa nos períodos das composições de longo fôlego, como se observa neste trecho de missiva de fevereiro de 1969:

Quando a sua carta chegou, eu já estava no meio da partitura do Concerto $n^{\circ} 4$. Afinal, resolvi diferente a orquestra. Não usei guitarra elétrica, depois de conhecer melhor as possibilidades do instrumento. Concluí que não me satisfazia completamente. Também "zampogna" foi eliminada. Afinal, a orquestra ficou

3 GUARNIERI, Camargo. Depoimento. In: SILVA, Flávio (Org.). Camargo Guarnieri: o tempo e a música. São Paulo: Imprensa Oficial; Rio de Janeiro: Funarte, 2001. p. 15-6.

4 TONI, Flávia Camargo, Correspondência Camargo Guarnieri - Mário de Andrade. In: SILVA, Flávio (Org.). Camargo Guarnieri: o tempo e a música. São Paulo: Imprensa Oficial; Rio de Janeiro: Funarte, 2001. p. 207. 
assim - 2 flautas + piccolo, 2 oboés + corne inglês, 2 clarinetes em si, 2 fagotes + contra-fagote, 4 Cornos, 3 trompetes (em Dó), 3 Trombones, 1 tuba, tímpanos, percussão (alguns instrumentos nacionais) celesta, vibrafone, xilofone, harpa, violas, violoncelos e contrabaixos $^{5}$. Não usei os violinos. No início me deu grande trabalho, a fim de me ambientar dentro da orquestra escolhida. Felizmente a 'matéria prima', como diz você, me facilitou a realização. Assim é que estou no fim do $3^{\circ}$ movimento e esta semana terminarei, creio eu. Assim é que estou gostando muito do resultado, pois agora já posso ter uma idéia do conjunto da obra. $02^{\circ}$ movimento saiu como você sugeriu, quase solístico para todos os instrumentos e usei uma orquestra menor. Quando você vir a partitura vai gostar, estou certo. A minha alegria é grande, creio que dei um grande passo à frente! ${ }^{6}$

Mas não foram aqueles os dois únicos mestres do compositor brasileiro; que nomeou, ainda, como seus professores, Ernani Braga e Sá Pereira, tendo-lhe sido este último também muito próximo. Aliás, a partir do momento em que deixou de estudar música com seus pais, o músico moço recebeu orientação de outros profissionais, tanto em Tietê quanto em São Paulo, no Brasil e na França ${ }^{7}$.

Aos 31 anos de idade, Camargo Guarnieri, compositor brasileiro premiado em concurso do Departamento de Cultura, maestro do Coral Paulistano, não era apenas uma promessa de compositor talentoso: tratava-se já de uma realidade quando, em 1938, escolheu estudar composição com Charles Koechlin. A bolsa que lhe foi concedida nesse ano pelo Conselho de Orientação Artística do Estado de S. Paulo deixava ao estudante a possibilidade de escolher seu destino, ou seja, o aluno poderia indicar onde e com quem desejaria estudar. No caso da música, os trajetos principais passavam pela Itália ou pela França - onde escolas e professores proliferavam e atendiam a diversos gostos e tendências. Assim, se a escolha de Paris por Camargo Guarnieri não é surpreendente, o que intriga é o nome do mestre escolhido: que buscava ele como formação específica em Charles Koechlin?

Camargo Guarnieri conhecia bem a obra de Koechlin, e sua primeira esposa, Lavínia Viotti, até mesmo executara a peça Novas Sonatinas $n^{\circ} 1$, em 1933, no mesmo programa em que

5 No original, “[...] 2 Fl + pic, 2 ob + Cor Ing, 2 Cl B, 2 Fag + C. Fag, [...]”.

6 GUARNIERI, Camargo. Carta para Lamberto Baldi, São Paulo, 19 de fevereiro de 1969. Série Correspondência, Fundo Camargo Guarnieri, Instituto de Estudos Brasileiros, Universidade de São Paulo.

7 VERHAALEN, Marion. Camargo Guarnieri: expressões de uma vida. São Paulo: Edusp, Imprensa Oficial, 2001. p. 21-2. 
figuravam as estréias do Ponteio $n^{\circ} 2$, do Ponteio $n^{\circ} 3$ e do Choro torturado. À obra teórica do professor francês ele tinha acesso na biblioteca particular de Mário de Andrade, que, além de assinar todos os principais periódicos musicais europeus, já lera e fichara Précis des règles du contrepoint, Études sur l'écriture de la Fugue, Études sur le Choral d'École, Traité de l'harmonie, entre outros. No entanto, outros professores e compositores italianos e franceses eram também bastante atuantes, freqüentavam tanto as páginas de periódicos quanto as de programas de concertos.

Um primeiro levantamento de dados mostrou que o mestre francês ministrava aulas particularmente para uma gama variada de alunos do Canadá, Estados Unidos, Japão, França e Portugal. Nesse sentido, um aluno brasileiro vislumbraria a possibilidade de Koechlin congregar ao seu redor os alunos estrangeiros que estudavam fora dos Conservatórios. Entretanto, Nadia Boulanger também já gozava de grande fama, acolhendo alunos talentosos das Américas (dos Estados Unidos, principalmente).

Charles Koechlin (1867/1950), membro da burguesia da Alsácia, nasceu em Paris, onde seguiu a carreira militar abraçando tardiamente a música em 1889. No Conservatório, além de estudar harmonia com Taudou, teve Massenet, Fauré e Gédalge como professores. Aos 42 anos, em 1909, profissional respeitado, integrou o comitê fundador da Sociedade Musical Independente, grupo que unia forças para aclamar a música de Debussy, bem como a criação livre, e que não mais encontrava abrigo junto à já antiga Sociedade Nacional ${ }^{8}$.

Conhecido pela defesa incondicional da liberdade e pelo amor à natureza, Koechlin sempre foi tido como intelectual respeitado, apesar de sua aparência um tanto excêntrica. Professor particular, conferencista e crítico musical, jamais lecionou no Conservatório onde se graduara, mas foi autor de sólida bibliografia para jovens músicos.

A autonomia profissional deve ter sido útil a Koechlin nos longos períodos em que lecionou nos Estados Unidos (Berkeley) e no Canadá, ou ainda quando conseguiu acumular cursos na Schola Cantorum e na École Normale de Musique, entre 1935 e 1939. Neste último estabelecimento, vale dizer, como professor substituto da amiga Nadia Boulanger ${ }^{9}$.

8 Trabalho original de M. Duchesneau (L'avant-garde musicale à Paris de 1877 à 1939. Liège: Mardaga, 1997) analisa a vida musical e a organização social destas duas sociedades, além da Serenade e da Triton.

9 A coluna “Nouvelles”, do Le Monde Musical, de 4 de dezembro de 1938, traz nota informativa sobre a ida de Nadia Boulanger para os Estados Unidos (a. 49, n.12, p. 297). Pelos diários de Charles Koechlin, sabe-se que ele substituiu a colega professora na École a partir do dia $1^{\circ}$ de dezembro e até junho de 1939, pelo menos, permaneceu no cargo, ministrando dezoito aulas. 
Charles Koechlin era extremamente metódico e organizado - traço provavelmente herdado da carreira militar. Observa-se tal organização, por exemplo, na construção de um diário em que anotava, de forma sintética, as atividades dos três períodos do dia, como aulas ministradas, concertos freqüentados, o envio de cartas, o desenrolar de suas composições e conferências, os cuidados com os filhos e a esposa, entre outros ${ }^{10}$.

Entre setembro de 1938 e junho de 1939, Koechlin trabalhou diariamente, sem falhas, mesmo quando se ausentava da cidade. Seu catálogo de obras ganhou onze novos títulos, além dos artigos escritos para Humanité, La Révue Musicale, Révue Internationale de Musique e Pensée, bem como as conferências para rádios ou salões de música. Também acompanhou as atividades da Associação dos Intelectuais contra a guerra e freqüentou as conferências sobre física nuclear ou as de seus amigos falando sobre outros amigos, como a de Darius Milhaud sobre Erik Satie a que assistiu em dezembro de 1938.

Um olhar detido na relação de alunos de Charles Koechlin parece, num segundo momento, apontar para uma resposta, qual seja, a presença de Fernando Lopes Graça, português que inclusive perdera sua bolsa de estudos devido ao envolvimento com a política estudantil de seu país. 0 compositor e mestre francês era, declaradamente, simpatizante do comunismo, mas é pouco provável que a escolha dele por Guarnieri tenha sido por motivos ideológicos.

Para tentar entender por qual motivo Camargo Guarnieri elegeu aquele professor, consultei os acervos pessoais de ambos. Encontrei pistas principalmente na intimidade contemplada pelos diários de Charles Koechlin, nos cadernos com os exercícios de aula mantidos pelo aluno e na troca de $\operatorname{cartas}^{11}$. Uma vez que sabia, de antemão, que Lopes-Graça foi amigo de Guarnieri, mantive a intenção de coletar referências a ele nas notas dos outros dois músicos, com a esperança de que ajudassem a esclarecer a questão maior ${ }^{12}$.

Camargo Guarnieri chegou a Paris em 16 de julho de 1938, mas não procurou de imediato o professor. A primeira entrevista

10 Os diários de Charles Koechlin foram transcritos por sua filha, Magdeleine, e estão hoje à disposição para consulta na Fondation Gustav Mahler (Paris).

11 KOECHLIN, C. Journaux, setembro 1938/outubro 1939. Médiathèque, Fondation Gustav Mahler, Paris. GUARNIERI, C. Exercícios de contraponto. Série Estudos, Fundo C. Guarnieri, Instituto de Estudos Brasileiros, Universidade de São Paulo. As cartas trocadas entre professor e aluno pertencem aos dois fundos citados. 
ocorreu em 20 de setembro e, 10 dias depois, Koechlin enviou, pelo correio, melodia de um coral para que, uma vez realizado a quatro vozes, começassem as aulas, de fato, em 5 de outubro. Até 28 de dezembro eles se encontrarão mais 11 vezes e, durante o ano seguinte, entre janeiro e 14 de junho, outras 20, de forma um tanto irregular, tendo se encontrado amiúde em fevereiro e março, e com falhas a partir de abril, devido, entre outros motivos, a duas viagens do professor, uma ao Marrocos e outra à Bélgica.

Pelo que foi possível apurar nos diários do compositor francês, a partir de setembro de 1938 o nome de Lopes-Graça aparece, pela primeira vez. Em $1^{\circ}$ de fevereiro do ano seguinte, uma quarta-feira, surge novamente, como segue:

Aula para Guarnieri. Continuação da cópia do Quinteto e à noite também. Aula para Graça e para Sampaio. ${ }^{13}$

No mesmo ano de 1939, o nome de Lopes-Graça é mencionado nos dias 15 de fevereiro e 15 e 29 de março. Porém, ao que parece, até quando ele e Guarnieri tiveram aulas no mesmo dia, os compromissos não ocorreram em horários consecutivos de forma a possibilitar o encontro entre ambos, como se percebe nos apontamentos do dia 15 de março:

Aula para Guarnieri. Textos copiados para Miss Norman. Aula para Grosbayne. Escrevi cartas. Aula para Graça. Recopiei vários corais; escrevi cartas. ${ }^{14}$

Ou seja, a quantidade maior de aulas de Guarnieri parece traduzir interesses diversos dos dois alunos, Lopes Graça provavelmente mais voltado para o trabalho específico sobre

12 Ricardo Tacuchian pesquisou o acervo pessoal do compositor português e publicou algumas das missivas recebidas de Camargo Guarnieri a partir da década de 1950. (TACUCHIAN, R. Relações da música brasileira com Lopes-Graça. Brasiliana: Revista Quadrimestral da Academia Brasileira de Música, Rio de Janeiro, ABM, n. 17, p. 12-20, maio 2004). 0 III Ciclo de Cultura Musical de Lisboa (Lisboa, Associação Acadêmica da Faculdade de Direito de Lisboa, Fundação Calouste Gulbenkian, 1966.) organizou a cronologia da vida e obra de Lopes-Graça, mas não há detalhes sobre o período vivido por ele, na França, na década de 1930. Por outro lado, em seu Musicália (Bahia: Livraria Progresso, 1960. p. 121) o músico lisboeta presta homenagem ao mestre por ocasião do falecimento deste, em 1950.

13 KOECHLIN, C. Jounaux. 1 de fevereiro de 1939, página 1694 da transcrição de Magdeleine Koechlin. As outras referências às aulas de Lopes Graça encontram-se às páginas 1696, 1699 e 1701. Fundação Gustav Mahler, Paris.

14 Ibid. 
composição. De fato, nas cartas e no caderno do moço brasileiro foi possível capturar certa rotina: as aulas eram formais, o professor enviava os exercícios e o aluno preparava-os para a semana seguinte. Entre outubro e dezembro de 1938, trabalharam principalmente: 1) Contraponto sobre temas de Bach e do próprio Koechlin e 2) Fuga, a partir do mês de novembro, sobre temas de César Franck, Gounod e Bizet. Os exercícios não eram propostos no mesmo dia da aula, e sim enviados pelo correio.

Quase diariamente Charles Koechlin escrevia cartas, inclusive para Guarnieri. 0 hábito se explica não apenas pelo fato de ele morar a 50 metros do correio, mas sobretudo pelas normas de boa educação dos homens daquele tempo. No entanto, o fato não deixa de ser curioso porque, além de encontrar o aluno às quartas-feiras, eles moravam muito perto: o número 29 da rue Claude Bernard fica a 900 metros do número 26 da rue des Boulangers, residência do mestre francês. Até 27 de outubro de 1939, véspera do regresso ao Brasil, o discípulo recebeu 21 cartas, a maior parte delas escritas de Paris, pois uma foi enviada de Bordeaux, uma de Casablanca (Marrocos) e as últimas e mais longas, de Villers sur Mer (França).

Para um jovem compositor vindo do outro lado do Atlântico como Camargo Guarnieri, a cidade de Paris tinha muito a oferecer, já que seus palcos viviam repletos de boas apresentações. A temporada de concertos do segundo semestre de 1938 apresentava inúmeras opções entre as récitas da Sociedade de Concertos Sinfônicos, a Orquestra Sinfônica de Paris, a Concertos Lamoureux, a Pasdeloup, ou a Sociedade Filarmônica de Paris. Foi com esta última que Guarnieri se emocionou fortemente ao assistir, em dezembro, a Le Nouvel Âge, de Markewitch, sob direção de Herman Scherchen. Entusiasmado, no primeiro dia de 1939 escreveu para Mário de Andrade:

Se eu disser que gostei, minto; se disser que não gostei, minto ainda mais! Fiquei meio infeliz e feliz, contente e descontente, com vontade de chorar e rir, uma coisa louca!!! Durante a execução não consegui pensar nada, tal foi a minha estupefação. Tive a sensação que cada instrumento falava uma língua própria, ou melhor, que cada um discutia um assunto diferente do outro. Lembrei-me de Paris, onde cada qual expõe suas idéias sociais ou étnicas com a maior liberdade. Para Markevich não existe harmonia nem tonalidade. Mesmo na instrumentação (digo, orquestração) creio, ele não concebe à nossa moda! Cada instrumento grita, berra, discute à sua maneira. Até o bumbo tem personalidade!... Markevich é um gênio ou um louco! Eu sei que o público ficou frio e Maestro Scherchen ficou danado. Nem mesmo ele foi aplaudido. Tenho enorme vontade de ter nas mãos uma dessas par- 
tituras, penso que a sua grafia deve ser interessante. Soube pelo Koechlin que Scherchen considera Markevich genial. É possível! Todas as vezes que anunciarem música dele, estarei firme para ouvir. Dizendo isso você já pode avaliar a minha impressão. ${ }^{15}$

A mesma Sociedade e regente promoveram outro concerto memorável para o compositor brasileiro, situação compartilhada com Charles Koechlin ao ouvirem o casal Ditta e Bela Bartók executar o concerto de Mozart para dois pianos, bem como a estréia francesa do concerto para dois pianos e percussão do compositor húngaro, em fevereiro de 1939.

Se Fernando Lopes Graça não teve oportunidade de escutar Bela Bartok na Salle Gaveau, é bem provável que tenha assistido a uma das apresentações em que se tocava música de seu professor. Apesar de pouco executado nos palcos franceses, em 1937, antes que Koechlin embarcasse para os Estados Unidos e o Canadá, verificam-se quatro concertos em Paris com obras suas e, no ano seguinte, seis outras apresentações na cidade, das quais também constam algumas de suas peças ${ }^{16}$.

Já no campo das realizações pessoais, o melhor proveito de Camargo Guarnieri foi a possibilidade de apresentar suas obras, a 7 e 12 de fevereiro de 1939, nas séries promovidas pela Révue Musicale e pela Orquestra Sinfônica de Paris, respectivamente. Segundo ele conta a amigos e parentes e o diário do professor não o nega, Charles Koechlin marcou presença nas duas récitas. A correspondência enviada pelo mestre, aliás, ajuda a delinear um quadro de atividade intensa na vida do músico brasileiro por ocasião dessas duas apresentações.

Em carta datada provavelmente de 5 de fevereiro, vésperas do concerto do dia 7, Koechlin propôs um horário para a aula semanal desculpando-se, antecipadamente, pois não sabia se iria poder ficar até o final da récita. De fato, além desta, o compositor septuagenário era aguardado, ainda, na Sala do Conservatório e, prevendo a incompatibilidade de horários, desejou sucesso ao aluno, elogiando-o:

15 TONI, Flávia Camargo, Correspondência Camargo Guarnieri - Mário de Andrade. In: SILVA, Flávio (Org.). Camargo Guarnieri: o tempo e a música. São Paulo: Imprensa Oficial; Rio de Janeiro: Funarte, 2001. p. 230-1.

16 M. Duchesneau demonstra com exaustivo levantamento de dados a intensidade da vida musical de Paris entre quatro Sociedades de médio e grande porte. 0 levantamento foi complementado com a leitura do periódico Le Monde Musical, de junho de 1937 a março de 1939, em cuja coluna, "Concerts du mois”, eram anunciadas as atividades dos salões de música, bem como das salas oficiais. DUCHESNEAU, M. L'avant-garde musicale à Paris de $1877 \dot{a}$ 1939. Liège: Mardaga, 1997. 
Não estou certo de permanecer até o fim do concerto - se não o vejo, desculpe-me, e acredite nos meus sinceros votos de sucesso. Suas melodias são muito boas e merecem ser muito apreciadas. ${ }^{17}$

Após o concerto de 12 de fevereiro, o mestre contou em outra cartinha ter-se encontrado com o crítico do Le Jour, Sauguet, que em breve escreveria sobre as obras ouvidas com a Orchestre Simphonique de Paris. Adiantou que o jornalista havia gostado muito da música de Guarnieri:

Estive com Sauguet ontem à noite e falando com ele sobre seu concerto na OSP e de sua notável intérprete, Sauguet me disse que tinha escrito sobre ela um artigo muito entusiasmado no Le Jour (o jornal onde ele faz crítica musical). Ele gostou muito dela e também gostou muito da sua música. Eu não sei a data do artigo mas deve ter sido pouco após o concerto. Você encontrará o número consultando a coleção do jornal nos escritórios do Jour, Avénue des Champs Élysées. Me apressei para contar, espero que isto agrade a todos. ${ }^{18}$

Após as duas apresentações de Camargo Guarnieri, as aulas seguiram o mesmo padrão anterior: o professor oferecia os temas, o aluno trabalhava-os em corais ou fugas. No entanto, mestre e discípulo estavam mais próximos. A 26 de fevereiro, um domingo, Koechlin visitou o aluno a fim de mostrar-lhe alguns vocalises para a "cantatrice brésilienne", ou seja, para Cristina Maristany. Trabalhou sobre esses vocalises ainda a 27 de fevereiro, 2, 3 e 4 de março, para mostrá-los mais uma vez a 5 do mesmo mês no apartamento da rue Claude Bernard. Por ocasião da primeira visita, uma foto registra o momento, confra-

17 KOECHLIN, Charles. Carta sem data, Série Correspondência, Caixa K (arranjo provisório), Fundo Camargo Guarnieri, Instituto de Estudos Brasileiros, Universidade de São Paulo. No original: “Je ne suis pas sûr de rester jusqu'à la fin du concert - si je ne vous vois pas, excusez moi et croyez à tous mes voeux de succès. Vos mélodies sont très réussies et méritent d'être très appréciées." (grifo do autor; tradução minha).

18 KOECHLIN, Charles. Carta de Paris, 19 de fevereiro de 1939, Série Correspondência, Caixa K (arranjo provisório), Fundo Camargo Guarnieri, Instituto de Estudos Brasileiros, Universidade de São Paulo. No original: “J'ai vu Sauguet hier soir et ayant parlé avec lui de votre concert de l'O.S.P. et de votre si remarquable interprète, Sauguet m'a dit qu'il avait écrit sur elle un article très enthousiaste dans Le Jour (c'est le journal où il fait la critique musicale). Il l'a beaucoup appréciée et il a aussi bcp [beaucoup] aimé votre musique. Je ne sais pas la date de l'article mais ce doit être très peu du temps après le concert. Vous trouverez le $\mathrm{n}^{\circ}$ en consultant la collection du journal aux bureaux du Jour, avenue des Champs Élysées. Je me hâte de vous écrire cela, j’espère que cela vous fera plaisir à tous." (grifo do autor; tradução minha). 
ternizando não apenas Guarnieri e seu professor, como também Anita - a segunda esposa do compositor brasileiro - e a professora dela, Andrée d'Ottemar, amiga de Charles Koechlin.

Uma vez na França, percebe-se, através da correspondência trocada com seus pais e, principalmente, com o amigo Mário de Andrade, que Camargo Guarnieri admirava e respeitava o mestre, embora sem compreender-lhe a personalidade. Aliás, o jovem brasileiro não falava francês e demonstrava certa impertinência em relação a Koechlin, considerando-o "orgulhoso" ${ }^{19}$.

Tal impressão certamente foi alterada durante a convivência com Charles Koechlin, em Paris. Aliás, o orgulho foi traço característico de Camargo Guarnieri ao longo da vida e é provável que ele se sentisse desconfortável pelo fato de sua Bolsa de Estudos atrasar com freqüência, ocasionando-lhe muitas vezes dificuldades financeiras. A 2 de maio, após algum tempo sem aulas, o mestre escreveu desejando que o aluno estivesse bem, tranqüilizando-o:

Caso não tenha recebido dinheiro para me pagar, venha assim mesmo, você me pagará quando puder. ${ }^{20}$

Mas é na carta de 14 de maio de 1939, escrita do navio, quando Koechlin ia de Casablanca para Marseille, que o professor deixa de ser protocolar e escreve pela primeira vez: "Mon cher éléve et ami". Até então ele o chamava de "Cher monsieur".

Poucos dias após, a 27 do mesmo maio, regressando da Bélgica, ele insistia:

Acrescento que se você estiver momentaneamente sem condições para me pagar, eu lhe darei aulas, sem problemas, a preço muito reduzido ou, eventualmente, sem cobrar. Que a questão dinheiro não o impeça de trabalhar. ${ }^{21}$

19 TONI, Flávia Camargo. Correspondência Camargo Guarnieri - Mário de Andrade. In: SILVA, Flávio (Org.). Camargo Guarnieri: o tempo e a música. São Paulo: Imprensa Oficial; Rio de Janeiro: Funarte, 2001. p. 228.

20 Tradução minha. No original: "Si vous n'aviez pas reçu de l'argent pour me régler, venez tout de même vous me paierez quand vous pourrez." KOECHLIN, C. Carta de Paris, 2 de maio de 1939 Série Correspondência, Caixa K (arranjo provisório), Fundo Camargo Guarnieri, Instituto de Estudos Brasileiros, Universidade de São Paulo.

21 Tradução minha. No original: “J'ajoute que si vous vous trouviez momentanément gêné pour me payer, je vous donnerai volontiers des leçons à prix très réduit ou même éventuellement, sans vous faire payer. Il ne faut donc pas que la question argent vous empêche de travailler." (grifo do autor) KOECHLIN, C. Carta de 27 de maio de 1939, sem local. Série Correspondência, Caixa K (arranjo provisório), Fundo Camargo Guarnieri, Instituto de Estudos Brasileiros, Universidade de São Paulo. 
É provável que nenhum dos dois soubesse que quatro dias após esta carta, a 31 de maio, eles se encontrariam pela última vez. A guerra e o verão separaram rapidamente professor e aluno.

Do conjunto de 21 cartas que Charles Koechlin enviou a Camargo Guarnieri, duas delas destoam porque não falam só de trabalho, tecendo planos para a continuidade da relação professor/ aluno. No verão de 1939, provavelmente antevendo uma situação política ainda mais complicada, Koechlin instalou sua família em Villers sur Mer, a três horas e meia de distância de Paris.

Passados os meses mais quentes, a 9 de setembro Koechlin procurou por seu aluno, dizendo: "não sei onde você está nestas horas trágicas"22. Ele estava preocupado com a situação financeira da família e perguntou se Guarnieri não gostaria de manter as aulas por correspondência.

A 30 de setembro, saudando Camargo Guarnieri como "Mon cher confrère et élève" e inquieto com a continuidade do trabalho do aluno, ofereceu sua residência em Villers sur Mer:

Se você pensa poder vir a Villers nós ficaremos muito felizes e até poderíamos talvez nos ajeitar para vos instalar no chalé ao lado do meu (que é meu, também, e onde eu acomodo minha filha com seu marido e as duas crianças). Há lugar e acredito que haveria a possibilidade de instalar uma cozinha independente. ${ }^{23}$

Ao dividir um pouco de sua rotina com o compositor brasileiro, Koechlin contou que estava trabalhando no Manual de orquestração e esperava arranjar, pelo menos, alunos particulares de matemática. A 10 de outubro, completando o plano para a possibilidade de Camargo Guarnieri se instalar no litoral, repete:

Nós organizamos as coisas de forma a que isto seja possível. Nós podemos lhe oferecer um quarto, suficientemente grande, e no térreo, uma sala para refeições, suficientemente grande também, que serviria igualmente de cozinha - nós instalamos um pequeno

22 Tradução minha. No original: "je ne sais pas où vous êtes en ces heures tragiques" KOECHLIN, C. Carta de Villers sur Mer, 9 de setembro de 1939. Série Correspondência, Caixa K (arranjo provisório), Fundo Camargo Guarnieri, Instituto de Estudos Brasileiros, Universidade de São Paulo.

23 Tradução minha. No original: "Si vous pensez pouvoir venir à Villers nous en serions très heureux et même nous pourrions peut-être nous arranger à vous installer dans le chalet à côté du mien (qui est à moi aussi, et où loge ma fille avec son mari et ses 2 enfants). Il y a la place et il y aurait, je crois, la possibilité d'y installer une cuisine indépendante.” KOECHLIN, C. Carta de Villers sur Mer, 30 de setembro de 1939. Série Correspondência, Caixa K (arranjo provisório), Fundo Camargo Guarnieri, Instituto de Estudos Brasileiros, Universidade de São Paulo. 
fogão - você poderia colocar um piano no quarto de dormir, ou alugando em Villers numa loja da cidade, ou alugando o piano de uma senhora que mora bem perto de mim, o que for mais em conta. Nós moramos no alto, próximos ao campo e a uma falésia de onde se tem uma bela vista sobre o mar. E nós ficaríamos encantados se vocês pudessem vir, os dois - nós faríamos as melhores condições de aluguel destes dois cômodos. Eu penso ficar aqui todo o inverno, procurar aulas de matemática, de francês, de latim e fazer algumas conferências sobre música. ${ }^{24}$

Guarnieri não pôde aceitar o convite do mestre e voltou para o Brasil em outubro de 1939. Um dos possíveis motivos para a recusa pode ter sido o fato de que o casal estava acompanhado de Dona Graça, mãe de Anita Guarnieri. A questão, que aqui pouco importa esclarecer, é passível, sem dúvida, de outras interpretações.

Somente a 27 de outubro Charles Koechlin ficou sabendo da partida do aluno e lastimou não tê-lo encontrado. Considerava, no entanto, a possibilidade de visitar o Brasil no ano seguinte:

Não poderia ir ao Brasil agora porque preciso ficar com os meus e no meu país - mas talvez, quem sabe, eu poderia ir no próximo verão, de 1940 - em julho-agosto (setembro ?) você poderia quem sabe usar de sua influência por lá para me programar algo. Ou em 1940, ou em 1941 ? (se eu não estiver velho demais até lá) ${ }^{25}$

24 Tradução minha. No original: "Nous avons arrangé les choses de façon que cela soit possible. Nous pouvons vous donner une chambre, assez grande, et au rezde-chaussée une salle à manger, assez grande aussi, qui servirait également, pour vous, de cuisine - nous y installons un petit fourneau - vous pourriez mettre un piano dans la chambre à coucher, soit en louant un piano à Villers dans un magasin du village, soit en louant le piano d'une dame propriétaire qui habite tout près de chez nous, ce qui reviendrait meilleur marché. Nous habitons sur la hauteur et on est tout de suite dans la campagne et sur la falaise d'où on a une belle vue sur la mer. Et nous serions enchantés si vous pouviez venir, tous deux - nous vous ferions les conditions les plus réduites possible pour la location de ces deux pièces. Je pense rester ici tout l'hiver, chercher à donner des leçons de mathématiques, de français, de latin et faire quelques conférences sur la musique." KOECHLIN, C. Carta de Villers sur Mer, 10 de outubro de 1939. Série Correspondência, Caixa K (arranjo provisório), Fundo Camargo Guarnieri, Instituto de Estudos Brasileiros, Universidade de São Paulo.

25 Tradução minha. No original: "Il ne serait pas question pour moi d'aller au Brésil en ce moment car je dois rester avec les miens et dans mon pays, - mais peut-être bien pourrais-je y aller l'été prochain, de 1940 - en Juilletaoût (Septbre ?) vous pourrez peut être user de votre influence là-bas pour m'y faire avoir un engagement. Soit en 1940 soit en 1941 ? (si je ne suis pas trop vieux alors)" KOECHLIN, C. Carta de Villers sur Mer, 27 de outubro de 1939. Série Correspondência, Caixa K (arranjo provisório), Fundo Camargo Guarnieri, Instituto de Estudos Brasileiros, Universidade de São Paulo. 
Três meses mais tarde, a 11 de fevereiro de 1940, ainda em Calvados, o professor contou um pouco de seu trabalho para Camargo Guarnieri:

Eu trabalhei muito nos últimos tempos. - Orquestrei os dois poemas sinfônicos inspirados no Livre de la Jungle, concluído em agosto passado - "La Loi de la Jungle" foi fácil de orquestrar, é como um grande coral monódico, mas o Bandar-Log (os Cisnes) foram de realização bastante difícil por causa do grande número de partes e do equilíbrio a ser mantido entre os diversos tipos de instrumentos. Ao escutar saberei se fui bem ou se cometi alguns enganos (o que seria bem possível). Será tocada em maio, na Rádio de Bruxelas, minha Symphonie d'Hymnes, e em junho minhas várias peças sobre o Livre de la Jungle. Serão provavelmente bem tocadas porque o maestro e a orquestra da I.N.R. são excelentes.

Atualmente eu copio as partes de orquestra e isto é um trabalho enorme. Sobretudo para as estantes duplas das cordas! E o scherzo dos Cisnes tem muitas notas... acredito ficar nisto o próximo mês, se eu consigo terminar neste mês a Loi de la Jungle. Deixei um pouco de lado meu Tratado de Orquestração, trabalharei nele mais tarde. No momento é preciso copiar o material - e depois tenho em projeto um grande poema sinfônico em 3 partes (baseado numa história admirável de meu tio, o filósofo Ch. Dollfus) sobre o destino humano - mas isto não será terminado tão cedo. ${ }^{26}$

26 Tradução minha. No original: “J’ai beaucoup travaillé ces derniers temps - J'ai orchestré les deux poëmes symphoniques d'après le Livre de la Jungle, que j'avais finis en août dernier - 'La Loi de la Jungle' était facile à orchestrer, c'est comme un grand choral monodique, mais les Bandar-Log (les Singes) étaient d'une réalisation fort difficile à cause du gd [grand] nombre de parties et de l'équilibre à garder entre différentes sortes d'instruments. À l'audition je verrai si j'ai réussi, ou si j'ai fait quelques erreurs (ce qui serait bien possible). On doit jouer à la Radio de Bruxelles, en mai, ma Symphonie d'Hymnes, et en Juin mes diverses pièces sur le Livre de la Jungle. Cela sera probablement très bien joué car le chef d'orch. et l'orchestre de l'I.N.R. sont excellents.

En ce moment je copie les parties d'orchestre et cela constitue un gros travail. Surtout pour les doubles des pupitres d'instrts à cordes ! Et le scherzo des Singes a beaucoup de notes... je compte m'y mettre le mois prochain, si je puis avoir fini ce mois-ci pour la Loi de la Jungle. J'ai laissé de côté provisoirement mon Traité de l'orchestration, j'y travaillerai plus tard. Pour l'instant il me faut copier ce matériel - et puis j'ai aussi en projet un grand poëme symphonique en 3 parties (d'après une "nouvelle" admirable de mon oncle le philosophe Ch. Dollfus) sur la destinée humaine - mais ce ne sera pas fini de sitôt." KOECHLIN, C. Carta de Villers sur Mer, 11 de fevereiro de 1940. Série Correspondência, Caixa K (arranjo provisório), Fundo Camargo Guarnieri, Instituto de Estudos Brasileiros, Universidade de São Paulo. 
0 mestre estava curioso com a possibilidade de ministrar um "curso" no Brasil, mal sabendo que entre nós a situação econômica e política também era muito conturbada, apesar de extremamente diversa daquela dos países que já estavam na guerra.

Só terminada a grande guerra, em maio de 1946, Camargo Guarnieri recebeu nova carta de seu professor, resumindo as atividades dos últimos cinco anos e apontando especialmente para

uma segunda sinfonia e uma Oferenda musical sobre o nome de Bach que eu orquestrei recentemente. Meu Tratado de Orquestração está na impressão (na casa Eschig) mas não vai depressa. A obra tem 4 grandes volumes, e só estão gravados o $1^{\circ}$ volume e a metade do segundo. Eu continuo sempre com as aulas, mas me reservo tempo para trabalhar. Me dizem que, fisicamente (e suponho que intelectualmente) eu não mudei - e eu bem quero crer, mas por quanto tempo ainda vai ser assim? No aguardo, me lembro de seu projeto, de me levar ao Brasil para cursos de polifonia modal e de Fuga. Seria uma grande alegria para mim se este projeto se realizasse um dia, por exemplo no verão (= inverno no Brasil) de 1947: este ano não terei tempo. ${ }^{27}$

Até sua morte, Koechlin escreveu ainda em dezembro de 1946, junho de 1947, julho de 1948, sempre de forma muito amigável e perguntando sobre as possibilidades de uma visita ao Brasil, para proferir conferências. Sentia-se, então, orgulhoso pelo fato de ter sido homenageado pela S.I.M.C. (Société Internationale de Musique Contemporaine), como membre d'honneur, posição até então ocupada apenas por Falla, Ravel, Roussel, Bartók, Strawinsky et R. Strauss.

Pelo conhecimento que Camargo Guarnieri tinha da obra teórica de Koechlin, via biblioteca particular de Mário de Andrade, a escolha do mestre não foi aleatória. Porém, se entre

27 Tradução minha. No original: "une 2de Symphonie, et une Offrande musicale sur le nom de Bach que j’ai orchestrée récemment. Mon Traité de l'Orchestration est à la gravure (chez Eschig) mais cela ne va pas vite. L'ouvrage comporte 4 gros volumes, et seuls sont gravés le 1er vol. et la moitié du second. Je donne toujours des leçons, mais je me réserve du temps pour travailler. On me dit que, physiquement (et intellectuellement, je suppose) je n'ai pas changé - je veux bien le croire, mais pour combien de temps serai-je encore valide? En attendant, je me souviens du projet que vous aviez eu, de me faire venir au Brésil pour des cours de polyphonie modale, et de Fugue. Ce serait une grande joie pour moi si ce projet pouvait se réaliser un jour, par exemple pour l'été (= hiver au Brésil) de 1947: - cette année je n'en aurais pas le temps." KOECHLIN, C. Carta de Paris, maio de 1946. Série Correspondência, Caixa K (arranjo provisório), Fundo Camargo Guarnieri, Instituto de Estudos Brasileiros, Universidade de São Paulo. 
os periódicos da mesma coleção também era possível conhecer a ideologia do compositor francês, não há elementos suficientes na biografia do jovem músico para se afirmar que houvesse, ainda, simpatia pelos ideais políticos do professor. 0 mesmo, certamente, não se poderá dizer sobre os motivos que direcionaram a escolha de Fernando Lopes-Graça. No entanto, em 1958, quando os dois homens maduros seguramente se conheceram, muita coisa havia mudado na vida de ambos e Guarnieri já possuía, então, um perfil político melhor definido.

Já compositor de sólida reputação, certa vez Camargo Guarnieri escreveu para uma amiga que estava infeliz por mudar novamente de professor, obrigada que era a rever certos procedimentos técnicos. Disse ele:

Quando fui à Europa, como prêmio de viagem, depois de passar por um concurso público, escolhi Paris como porto seguro para as minhas atividades. Em Paris, procurei o grande músico (digo assim, por considerar este termo o maior, quando é usado com propriedade) Charles Koechlin. Quando fui procurá-lo, em vez de fazer como qualquer outro compositor o faria, disse-lhe que queria estudar harmonia com ele. Perguntou-me: o senhor já estudou? Respondi-lhe: Não! Desejo aprender desde o começo. E assim fiz, minha amiga. Começamos desde o comecinho, estudando intervalos, os acordes de 3 sons (as tríades), de 4 sons (tétrades), enfim tudo, tudo. Fiz isso porque sentia algumas dúvidas que no Brasil ninguém havia me ensinado. Depois de algum tempo ele me conheceu melhor dai tomamos outro rumo no estudo, mas eu já havia aproveitado tudo quanto desejava da grande sabedoria dele. ${ }^{28}$

Eis, provavelmente, o que explica o fato de Camargo Guarnieri manter uma fotografia autografada de seu mestre em sua mesa de trabalho, imagem que o acompanhou até o final da vida, a 13 de janeiro de 1993.

Recebido em: 13 Fev. 2007 Aprovado em: 22 Maio 2007

28 GUARNIERI, Camargo. Carta para Zuleica Guedes, São Paulo, 5 de agosto de 1955. Série Correspondência, Caixa G (arranjo provisório), Fundo Camargo Guarnieri, Instituto de Estudos Brasileiros, Universidade de São Paulo. 